\title{
0 ENCONTRO DE SABERES COMO EXPANSÃO EPISTÊMICA: PERCURSOS NA UNIVERSIDADE FEDERAL DOS VALES DO JEQUITINHONHA E MUCURI
}

\author{
ANA FLÁVIA ANDRADE FIGUEIREDO ${ }^{1}$ \\ JOSÉ CLÁUDIO LUIZ NOBRE ${ }^{2}$ \\ LUCIANA RESENDE ALLAIN ${ }^{3}$ \\ SILVIA REGINA PAES ${ }^{4}$
}

\begin{abstract}
RESUMO
Buscamos aqui entrelaçar elementos da política do Encontro de Saberes no contexto das instituições universitárias no Brasil e, em especial, refletir, a partir da experiência de sua implementação na Universidade Federal dos Vales do Jequitinhonha e Mucuri, como tal política potencialmente gera transformações profundas, de fundamentos epistêmicos a questões estruturais tanto da ordem administrativa, pedagógica quanto das relações dentro do ambiente acadêmico. Primeiramente contextualizamos o histórico de implementação da Política do Encontro de Saberes e, em seguida, descrevemos a memória, desde a implementação na UFVJM até 0 momento atual, evidenciando-se o locus de vivência situada em seus territórios de abrangência. Ao relembrarmos nossos passos, destacamos o sentido de coletividade e afetividade que nos marcou, a construção de novos espaços pedagógicos e o compartilhamento circular de conhecimentos, advindos da potência da presença das mestras e mestres e da Pedagogia de Alternância.
\end{abstract}

\section{PALAVRAS-ChaVe \\ Encontro de Saberes; Universidade Federal dos Vales do Jequitinhonha e Mucuri; Descolonização.}

\section{THE MEETING OF KNOWLEDGE AS EPISTEMIC EXPANSION: ROUTES ATTHE UNIVERSIDADE FEDERAL DOS VALES DO JEQUITINHONHA E MUCURI}

\begin{abstract}
We intend here to intertwine elements of the Meeting of Knowledges Policy in the context of university institutions in Brazil, specially, we intend to reflect, from the experience of its implementation at the Universidade Federal dos Vales do Jequitinhonha e Mucuri, how such policy potentially generates profound transformations, from epistemic to structural issues of administrative and pedagogical order, besides the relations within the academic environment. First, we update the implementation history of the Meeting of Knowledges Policy and then we describe the memory of its implementation until the present time, evidencing the locus of experience situated on UFVJM territories. As we recall our steps, we highlight the meaning of the collectivity and affectivity that marked us as a group; the construction of other pedagogical spaces and circular
\end{abstract}

\footnotetext{
${ }^{1}$ Professora Adjunta na Universidade Federal dos Vales do Jequitinhonha e Mucuri e Integrante da Comissão Encontro de Saberes na UFVJM.

${ }^{2}$ Filho do Jequitinhonha, integrante da Comissão Encontro de Saberes e Professor Adjunto da Licenciatura em Educação do Campo da UFVJM.

${ }^{3}$ Professora Adjunta na Universidade Federal dos Vales do Jequitinhonha e Mucuri e Integrante da Comissão Encontro de Saberes na UFVJM.

${ }^{4}$ Professora Associada da Universidade Federal dos Vales do Jequitinhonha e Mucuri e Integrante da Comissão Encontro de Saberes da UFVJM.
} 
sharing of knowledge, that comes from the power of the masters presence at the university and the alternation pedagogy model.

\title{
KEYWORDS \\ Meeting of Knowledges Policy. Universidade Federal dos Vales do Jequitinhonha e Mucuri. Decolonization.
}

\section{LA RENCONTRE DES AVOIRS COMME UNE EXPANSION ÉPISTÉMIQUE: LES PARCOURS À L'UNIVERSITÉ FÉDÉRALE DES VALLÉES DU JEQUITINHONHA ET MUCURI}

\begin{abstract}
RÉSUMÉ
Nous cherchons ici à entrelacer des éléments de la politique de la Rencontre des savoirs dans le contexte des institutions universitaires au Brésil et, en particulier, refléter, à partir de l'expérience acquise au cours de sa mise en œuvre à l'Université Fédérale des Vallées de Jequitinhonha et Mucuri, en tant que telle politique génère potentiellement de profondes transformations, des fondements épistémiques aux problèmes structurels d'ordre administratif, pédagogique et des relations au sein de l'environnement académique. Dans un premier temps, nous contextualisons l'historique de mise en œuvre de la Politique de la Rencontre des Savoirs puis nous décrivons la mémoire, depuis sa mise en œuvre à l'UFVJM jusqu'à l'instant présent, en montrant le locus d'expérience situé dans ses zones de couverture. En rappelant nos pas, nous mettons en évidence le sens de la collectivité et de l'affection qui nous a marqués, la construction de nouveaux espaces pédagogiques et le partage circulaire des connaissances, découlant du pouvoir de la présence des des maîtres et des maîtresses et de la Pédagogie de l'Alternance.
\end{abstract}

MOTS CLÉS

Rencontre des savoirs. Universidade Federal dos Vales do Jequitinhonha e Mucuri. Décolonisation.

\section{EL ENCUENTRO DEL SABERES COMO EXPANSIÓN EPISTÉMICA: RUTAS EN UNIVERSIDADE FEDERAL DOS VALES DO JEQUITINHONHA E MUCURI}

\section{RESUMEN}

Buscamos aquí entrelazar elementos de la política del Encuentro de Saberes en el contexto de las instituciones universitarias en Brasil y, en particular, reflexionar, desde la experiencia de su implementación en la Universidad Federal de los Valles de Jequitinhonha y Mucuri, como tal política potencialmente genera transformaciones profundas, desde fundamentos epistémicos hasta cuestiones estructurales tanto de la administración, pedagógica y de las relaciones dentro del contexto académico. En primer lugar, contextualizamos la historia de la implementación de la Política del Encuentro de Saberes y luego describimos la memoria, desde la implementación en UFVJM hasta el momento actual, evidenciando el locus de experiencia ubicado en sus territorios de cobertura. Recordando nuestros pasos, destacamos el sentido de colectividad y afecto que nos marcó, la construcción de nuevos espacios pedagógicos y el intercambio circular de conocimientos, procedentes del poder de la presencia de maestras y maestros y de la Pedagogía de la Alternancia.

Encuentro de Saberes. Universidade Federal dos Vales do Jequitinhonha e Mucuri. Descolonización. 


\section{INTRODUÇÃO}

O presente artigo busca entrelaçar elementos da política do Encontro de Saberes ${ }^{5}$ no contexto das instituições universitárias no Brasil, em especial, refletir, a partir da experiência de sua implementação na Universidade Federal dos Vales do Jequitinhonha e Mucuri, como tal política potencialmente gera transformações profundas, de fundamentos epistêmicos a questões estruturais, tanto da ordem administrativa, pedagógica quanto das relações dentro do ambiente acadêmico.

Entendemos que os desafios e as dificuldades de investimento/financiamento, administrativas e pedagógicas ainda são grandes (do que trataremos adiante), entretanto, com uma história de implementação de apenas dez anos, compreendemos que o E.S é um importante pilar das políticas de ação afirmativa e, sobretudo, uma prática fundamental de descolonização de nossas universidades. Trata-se de descolonizar o saber e o fazer universitários, construindo, promovendo e defendendo espaços concretos em que várias epistemes possam dialogar horizontalmente, numa relação de equidade.

Optamos aqui por, primeiramente, contextualizar o histórico de implementação da Política do E.S ${ }^{6}$. Em seguida, descrevemos a memória na UFVJM, desde a implementação até o momento atual, evidenciando-se o locus de vivências situadas nos territórios de abrangência da instituição.

Ao relembrarmos nossos passos, destacamos o sentido de coletividade e afetividade que nos marcou, a construção de novos espaços pedagógicos e compartilhamento circular de conhecimentos, advindos da potência da presença das mestras e mestres, da Pedagogia de Alternância dentro do projeto e, por fim, seus desdobramentos, inclusive durante a atual pandemia. Este texto, vale ressaltar, foi pensado e escrito de forma coletiva, como um princípio e exercício contínuo da comissão responsável pelo E.S em nossa universidade.

Destacamos o papel da rede afetiva que tem se formado em torno desta política. Nossos colegas da Comissão na UFVJM, assim como o próprio professor José Jorge de Carvalho, coordenador do Instituto Nacional de Ciência e Tecnologia de Inclusão no Ensino Superior e na Pesquisa (INCTI/UnB/CNPq), principal mentor e articulador da Política do E.S, além das mestras e mestres com os quais temos construído laços, são interlocutores fundamentais na construção das reflexões que aqui apresentamos. Importante ressaltar,

\footnotetext{
${ }^{5}$ Durante o texto utilizaremos a abreviatura E.S.

${ }^{6}$ Universidades que já implementaram: UnB, UFMG, UFJF, UFSB, UFPA, UECE, UFCA, UFF, UFRGS, UFVJM, UFRR, UFRJ, UNILAB, USU e, fora do Brasil: a Pontifícia Universidad Javeriana, na Colômbia; Universidades com experiências parciais: UFES, FURG, UFRN; Universidades que já aprovaram o projeto: UFPB, (UFU), Universidade do Estado de Santa Catarina (UDESC).; Universidades com experiências parciais: Universidade Federal do Espírito Santo (UFES), Universidade Federal do Rio Grande (FURG), Universidade Federal do Rio Grande do Norte (UFRN); Universidades que já aprovaram o projeto: UFPB, UFU, UDESC.
} 
ainda, que os colegas aos quais nos referimos e que compõem a Comissão Encontro de Saberes na UFVJM são docentes, técnicos administrativos, discentes (alguns representantes de comunidades tradicionais), mestras e mestres da tradição e da cultura popular dos Vales do Jequitinhonha e Mucuri.

\section{A POLÍTICA ENCONTRO DE SABERES}

A partir de documentos produzidos pelo INCTI e de artigos publicados por pesquisadores diretamente ligados a experiências de implementação do projeto em suas respectivas instituições, traçamos nesta seção uma breve contextualização histórica e conceitual da Política. Defendemos ser este um importante caminho de expansão/revolução epistêmica, pluriontológica e, assim, de permanência, salvaguarda e valorização de sujeitos e saberes historicamente invisibilizados e silenciados pela exclusão estrutural que opera em nossas instituições universitárias.

O INCTI, segundo Carvalho, em entrevista concedida em 27 de julho de 2020, teve como embrião os Seminários Nacionais e Internacionais de Cultura Popular (especialmente o Seminário Nacional de Políticas Públicas para as Culturas Populares, realizado pelo então Ministério da Cultura em 2005, em Brasília, e o II Encontro Sul-americano das Culturas Populares, realizado na cidade de Caracas, Venezuela ${ }^{7}$ ). Sobre o evento de 2005, Carvalho afirma:

"Esse encontro foi um marco histórico na luta pela afirmação das culturas populares brasileiras, primeiro devido à sua dimensão inédita, ao reunir quase mil mestres, mestras e brincantes na capital do país; segundo, por ter permitido a consolidação de uma plataforma política em que as vozes de mestres passaram a fazer parte imprescindível de qualquer projeto de apoio estatal às nossas tradições populares" (2010, p.72).

Tais eventos resultaram na escrita e publicização das duas cartas assinadas pelas delegações presentes. A segunda, em especial, é assinada por "mestres, mestras, artistas, pesquisadores das culturas populares, povos originários, comunidades afro-americanas e representantes da sociedade civil e dos Estados". Em tais documentos fica explícita a demanda pela criação de mecanismos que favoreçam a inclusão das culturas populares nos processos educativos formais e informais.

Ainda em 2008, foi aberto o Edital do Programa Institutos Nacionais de Ciência e Tecnologia ${ }^{8}$, conduzido pelo então Ministério da Ciência e Tecnologia (MCT), por meio do Conselho Nacional de Desenvolvimento Científico e Tecnológico (CNPq). Uma rede de

\footnotetext{
${ }^{7}$ A carta, lida publicamente no dia 28 de novembro de 2008, é o primeiro manifesto sul-americano em defesa das culturas populares que foi redigido conjuntamente e a partir das vozes dos próprios mestres e artistas das expressões culturais tradicionais do nosso continente" (CARVALHO, 2010, p. 72).

${ }^{8}$ Mais informações sobre os INCTs em: htttp://inct.cnpq.br/sobre/ Acesso em 17 de agosto de 2020.
} 
pesquisadores, coordenada pelo professor José Jorge de Carvalho, submete a proposta de criação do INCTI $^{9}$ e, conquistado o edital, apresenta um projeto para a Portaria Normativa Interministerial $n^{\circ} 1$ de 04 de outubro de 2007, voltada à incorporação dos mestres de ofício e das artes tradicionais nos vários níveis de ensino.

O E.S nasce, então, como um projeto estruturante do INCTI e tem sua gênese a partir de uma parceria estabelecida junto à Universidade de Brasília (UnB), sede do INCTI, ao CNPq, ao MCT, ao Ministério da Educação (MEC) e ao Ministério da Cultura (MinC). Uma política que provoca o reconhecimento e valorização de mestres e mestras de notório saber nas várias áreas de ensino, pesquisa, criação e realização, ao promover diálogos e integração entre os conhecimentos acadêmicos e os saberes tradicionais das culturas populares, indígenas e quilombolas no âmbito das universidades brasileiras (INCTI, 2019).

Segundo Carvalho e Flórez (2014), a aposta política do E.S está assentada no propósito de que as ciências sociais reconheçam os saberes tradicionais e populares não apenas como campos/objetos de estudos, mas como referentes de conhecimentos tão válidos quanto os 'modernos' e que reconheçam os sábios tradicionais como pares, aptos a ocuparem os espaços de docência, pesquisa e extensão em nossas instituições. Para nós, cabe à universidade um compromisso ético e político de mitigar tamanha dívida histórica, por meio da transmissão e da circulação dos saberes dos povos tradicionais, prioritariamente, por suas mestras e mestres.

O E.S. é resultado de uma confluência de diversos elementos. O contexto de uma política educacional entrelaçada à cultura e à ciência, fontes de financiamento, demandas das culturas populares sendo debatidas em instâncias governamentais, construção do Plano Nacional de Cultura (2010), o momento de grande força das Redes de Culturas Populares, criação de sistemas de consulta e deliberação popular, tais como os seminários e conselhos nacionais, estaduais e municipais de cultura e, muito especialmente, à implementação da política de cotas no ensino universitário. Importante desde já reforçar que a adoção de medidas de ações afirmativas, tal qual a política de cotas, possui uma dimensão redistributiva, ao permitir o maior acesso de negros e indígenas ao sistema universitário, possibilitando provocações e transformações sociais tanto na perspectiva da mobilidade social dos sujeitos, como na própria dinâmica de construção de nossas relações em sociedade. Ao incluir as mestras e mestres que representam uma complexidade de epistemes, o E.S. provoca uma reestruturação dos conhecimentos acadêmicos, "marcado por fronteiras disciplinares e por uma atitude cronicamente eurocêntrica, que privilegia os saberes da ciência ocidental moderna" (CARVALHO; ÁGUAS 2015, p.1018).

\footnotetext{
${ }^{9}$ Mia informações: http://inct.cnpq.br/web/inct-i. Acesso em 17 de agosto de 2020. 
Pensando sobre os diversos níveis de uma educação intercultural (interculturalidade discente, filosófica, formativa, docente e epistêmica), compreendemos que o E.S. é um pilar fundamental, da educação básica à universitária, e atravessa em diferentes medidas cada uma destas dimensões. Além disso, com a inclusão dos saberes indígenas, afrodescendentes e populares como parte do cânone dos saberes válidos, em igualdade de condições com os saberes ocidentais modernos, potencialmente impacta-se a constituição dos currículos, das ementas, dos projetos político-pedagógicos, da pedagogia extramuros. Desta forma, assim como as universidades indígenas e outras experiências que conquistam aos poucos espaço em nosso continente, este se apresenta como um caminho de reconexão com uma estrutura de conhecimento alicerçada na ancestralidade. Como reforçado por Aline Kaiapó:

(...) quando nós temos uma ancestralidade, nós conseguimos sim valorizar o nosso olhar epistêmico, de tudo ao nosso redor, e produzir o conhecimento científico ancestral, que é um conhecimento científico que tem compromisso com os povos, que tem compromisso com a dignidade dos seres vivos, que trata a água, os rios, o mar, como um ser de direito $(\ldots)^{10}$.

Um componente central, assim, é o da humanização ${ }^{11}$ de nossas pedagogias, das práticas e saberes em nossas instituições. Para Walsh (2010), isto depende de dois caminhos: o da descolonização e o do descolonizar-se, ou seja, precisamos de "apuestas (des)de el insurgir, re-existir y re-vivir", como processos de re-criação! Neste sentido, é preciso (des)aprender! O Encontro de Saberes nos possibilita, neste sentido, acionar outras habilidades, pelo sistema mundo e escolar eurocêntrico, moderno/capitalista, colonial/patriarcal, atrofiadas.

Acreditamos, por fim, que uma educação intercultural alimentada pela Política do Encontro de Saberes e da qual esta se alimenta, precisa conectar, ao leque de suas dimensões, as epistemologias feministas. Como defende a professora Juliana Flórez (2020), coordenadora do projeto na Universidad Javeriana (Colômbia), as investigações feministas e descolonizadoras possuem premissas mútuas e necessitam também ser inseridas em suas discussões. Corroboramos com Flórez para quem não pode haver descolonização de saberes se não houver uma política antipatriarcal, ou de superação do patriarcado, do racismo, das questões de classe.

Considerando-se que a violência de gênero é uma construção histórica colonialista que provoca profundas sequelas também entre as comunidades, de acordo com mestras e mestres com quem dialogamos, certamente, nossas instituições universitárias precisam ser

\footnotetext{
${ }^{10}$ Aline Ngrenhtabare Kaiapó e Edson Kaiapó em conversa ao vivo em 11 de agosto de 2020. Fonte: https://m.facebook.com/profile.php?id=100000767873122. Acesso em 11 de agosto de 2020.

11 O uso do termo humanizar não está relacionado a uma perspectiva antropocêntrica, do Humanismo eurocentrado universalista, que desconsidera o humano como plural, múltiplo e diverso. Ao contrário, busca considerar, (re)conhecer e integrar de forma simétrica saberes e práticas diversas, que contemplem o sentido de ser, de existir, de diferentes cosmovisões.
} 
repensadas também sob o recorte patriarcal que culmina na valorização de certos saberes funcionais para a lógica utilitarista e produtivista do capital. Nesse sentido, a descolonização dos saberes e, assim, o E.S., precisa também se tornar feminista, na perspectiva da contra colonialidade discutida por Santos (2019).

Assim, as práticas pedagógicas desenvolvidas no âmbito da política resultam do espaço de diálogo estabelecido entre os mestres e professores parceiros, que assumem o papel de anfitriões, verdadeiros parceiros afetivos, estabelecendo pontes entre os saberes e o cuidado amoroso com cada etapa e dimensão do projeto. Dentro deste, as ementas das disciplinas, assim como os projetos de pesquisa e extensão, devem ser construídas conjuntamente e em colaboração com as mestras e mestres, com suas comunidades, tendo em vista a necessidade de tensionar o processo secular, ainda vigente, de subalternização e hierarquização dos saberes tradicionais pelo modelo de conhecimento racional, monoepistêmico, eurocentrista e moderno, tipicamente produzido e transmitido nas universidades.

Um marco na superação da prática colonial com a qual a universidade ainda insere saberes tradicionais numa perspectiva de tomá-los como meros objetos de estudo foi a abertura do E.S. na Universidade de Brasília em 2010. Esta primeira edição da política contou com um Seminário Internacional para intercâmbio de experiências sul-americanas de inclusão dos saberes tradicionais nas universidades. Carvalho e Clara Águas relatam que a conferência magistral de abertura esteve a cargo de Mapulu Kamayurá, uma xamã do Parque Nacional do Xingu que a proferiu em seu idioma (Kamyurá). Práticas assim possibilitam que mestras e mestres protagonizem a circulação de seus saberes dentro do espaço universitário e permitem a chancela desse saber numa perspectiva de totalidade, sem a pretensão de substituir o conhecimento moderno, mas de estabelecer com ele um diálogo (inter)epistêmico. Para Carvalho e Águas,

\begin{abstract}
"A proposta baseia-se em uma perspectiva pedagógica que integra o pensar, o sentir e o fazer, o que sublinha seu caráter vanguardista, tanto em termos teóricos quanto metodológicos se pensamos no desequilíbrio entre essas dimensões do aprendizado nos cursos vigentes, os quais hipertrofiam uma delas ao preço de atrofiar as outras duas" (CARVALHO; ÁGUAS, 2015, p.1018, grifos nossos).
\end{abstract}

Com o mesmo espírito de uma confluência descolonizadora de saberes, a partir da experiência de implementação da política na UFVJM, e incorporação da vivência situada no seu território de abrangência, apresentaremos alguns dos princípios que foram base das estratégias e percursos definidos, que, de forma cíclica, lançam-nos, inclusive, a importantes desafios no campo teórico e metodológico, e a processos de reflexão-intervenção nas nossas próprias práticas.

\title{
O ENCONTRO DE SABERES: DESAFIOS DE IMPLEMENTAÇÃO NA UFVJM
}


A Universidade Federal dos Vales do Jequitinhonha e Mucuri, criada em 2005, fruto da política de expansão das instituições universitárias, alinhada ao processo de interiorização do ensino universitário público federal do Governo do Presidente Luiz Inácio Lula da Silva, está cravada em uma região de Minas Gerais que, por um lado, evidencia grande e diversa riqueza sociocultural, ancestral, de exemplos de luta e resistência de movimentos políticosociais e, por outro, está historicamente submetida a ações de violência territorial, seja através da exploração da monocultura de eucalipto, mineração, instalação de usinas hidrelétricas, alta concentração de renda em uma elite aristocrática, alto índice de analfabetismo, escassez de projetos concretos baseados na valorização e respeito aos modos de vida e saberes ancestrais. Daí resulta a responsabilidade ética e política da UFVJM ante à necessidade de reparações históricas nesse território.

Sabemos que os Vales, sobretudo o do Jequitinhonha, são representados como "miseráveis" pelos meios de comunicação de massa e têm sido plataformas de políticas colonialistas que buscam o silenciamento social, afetam a autoestima dos moradores locais e, de certa forma, fazem com que homens migrem aos grandes centros urbanos por acreditarem em promessas de uma vida melhor e sejam levados a uma rede de exploração do trabalho semi escravo em monoculturas de cana-de-açúcar, colheitas de café, soja e algodão do interior de São Paulo. Como agravante, em momentos de crise, como a da pandemia, a precariedade aumenta e atinge os mais jovens, colocando-os na mesma itinerância. Muitos deles, que estão na UFVJM, e pertencem a comunidades com as quais a Comissão do E.S. é composta e dialoga, levam à universidade suas histórias de vida socioculturalmente construídas.

Em 2012, dois anos após a primeira edição do E.S. na UnB, o Festival de Inverno, um dos principais eventos da cidade de Diamantina-MG, promovido pela Universidade Federal de Minas Gerais desde 1967, ganhou novos formatos e gerou uma circulação de expressões culturais que marcam profundamente não só os sujeitos diretamente envolvidos com o evento, mas também as instituições parceiras, entre as quais a própria UFVJM. Já naquele período, percebeu-se que o desenho criado para o festival, coordenado pelo professor César Guimarães, se aproximava e impulsionava novos caminhos institucionais de expansão e consolidação do E.S.

Em 2013, o evento, em sua segunda edição neste novo formato, contou com a curadoria de mestres participantes de sua edição anterior e realizou um Seminário com a presença do professor José Jorge. É fato que nas edições de 2012 e 2013, plantou-se uma semente entre um grupo de docentes da UFVJM, que também acompanhou, em 2014, a 
UFMG implementar o E.S, com apoio do INCTI, em formato diferenciado ${ }^{12}$ entre as IES da rede. E este se torna mais um passo de inquietação positiva do grupo de professores que, mesmo de longe, acompanha com interesse as potências dessa promissora experiência.

Em dezembro de 2017, com a vinda à Diamantina do Prof. José Jorge de Carvalho, a convite do Núcleo de Estudos em Literaturas, Artes e Saberes (NELAS/UFVJM/CNPq), com apoio do Grupo de Estudo dos Povos Indígenas de Minas Gerais (GEPIMG/UFVJM/CNPq), do Grupo Jequi de Saúde Coletiva (JEQUI/UFVJM/CNPq) e das Pró-Reitorias de Pesquisa, Ensino e Extensão, realizamos atividades que foram estruturantes do movimento pela constituição de uma Comissão responsável pelo desenvolvimento da Política na UFVJM, entre elas, uma palestra com o Professor José Jorge, na qual tivemos a presença de estudantes, docentes e técnicos administrativos de diversos setores e áreas da Universidade.

Este momento impulsionou reuniões entre as Pró-Reitorias de Pesquisa, Ensino e Extensão da UFVJM, com a presença de representantes da equipe responsável pelo E.S. na UFMG, que culminaram na articulação de ações emergentes na UFVJM, como a criação do NEABI (Núcleo de Estudos Afro Brasileiros e Indígenas). Tais reuniões também impulsionaram discussões acerca da potencialidade desta Política em atender indicadores de avaliação da graduação e pós-graduação, tais como, a inserção e impacto regional, social e cultural dos programas de pós-graduação na região, a relevância das atividades técnicas e científicas para as políticas de desenvolvimento microrregional, além da integração com cursos de graduação. Vale ressaltar, que, naquele momento, diversos cursos de graduação na UFVJM estavam na iminência de modificarem seus projetos pedagógicos a fim de atender a diretrizes nacionais do Ministério da Educação no tocante à incorporação, no currículo dos cursos, de questões relativas aos Direitos Humanos e Cidadania e à política para a Creditação da Extensão Universitária. Destacamos que a presença, em nossa universidade, do Prof. José Jorge e do então Pró-Reitor de Graduação da UFMG, Prof. Ricardo Takahashi, assim como o apoio da equipe de implementação na UFMG foi de fundamental importância para congregar um grupo de professores em torno desse objetivo comum, bem como para sensibilizar os gestores da UFVJM quanto à importância da implementação nesta universidade.

Cabe destacar, no entanto, que muito embora sejam inegáveis as contribuições desta política para atender aos indicadores avaliativos preconizados para a extensão universitária e para o ensino de graduação, foi na pós-graduação que encontramos o acolhimento necessário à sua efetiva implementação, conforme veremos mais adiante. A partir de então, foi realizada uma chamada pública e, assim, o grupo se amplia e passa a envolver também técnicos, discentes e comunidade externa. A partir desta ocasião e durante

\footnotetext{
12 Sobre o Programa de Formação Transversal na UFMG ver: BRASIL; GUIMARÃES; BICKEL; ERRICO; OLIVEIRA; BORTOLUS; MARQUEZ; MIRANDA. Proposta de Formação Transversal: Saberes Tradicionais. UFMG, 2014.
} 
o ano de 2018, as Pró-Reitorias de Graduação, Pesquisa e Pós-Graduação, Planejamento e Orçamento, e Extensão e Cultura, bem como a então Reitoria, foram convidadas a reuniões para refletirmos juntos sobre os caminhos para a plena integração do Encontro à nossa universidade. Assim, é criada a Comissão Encontro de Saberes pela Portaria № 1421, de 23 de maio de 2018 que designa seus membros com data retroativa à 21 de março de 2018 .

Na prática, a Comissão se reúne semanalmente ou quinzenalmente desde dezembro de 2017, possui um caráter interdisciplinar e é composta por docentes, técnicos administrativos representantes de Pró-Reitorias, discentes representantes de comunidades tradicionais dos Vales do Jequitinhonha e Mucuri e Comunidade Externa (da qual emanam mestras e mestres dos saberes tradicionais).

Desenvolveu-se, nesse período, o projeto de implementação (aprovado no âmbito da pós-graduação e já em plena execução) e o registro de um Programa de Extensão (o qual integra diversos projetos, eventos e ações) e, em 2020, iniciam-se algumas atividades no âmbito da pesquisa. Para nós, a participação efetiva de estudantes e técnicos; de integrantes da comunidade externa - como o fotógrafo Lori Figueiró e a consultora Viviane Fortes (ambos com atuação de mais de vinte anos no Vale do Jequitinhonha); e de mestres integrantes da Comissão, como Alê do Rosário (liderança quilombola de Chapada do Norte, Médio Jequitinhonha - in memoriam) e Mestra Lira Marques (eminente sabedora da arte do barro, do imaginário, das expressões e dos saberes do Vale do Jequitinhonha); são fundamentais para o nosso fortalecimento enquanto grupo com sentidos e pulsões em comum. Mestra Lira, que se tornou uma espécie de madrinha de nossa Comissão e colocounos para dançar, jogar versos, cirandar, em reunião presencial em 09 de maio de 2018, reforça: "É preciso valorizar as pessoas, e isso é ajudar naquilo que elas já possuem".

A seguir, depoimento da estudante Jéssica Alcântara, integrante da Comissão:

Minha chegada como membra da Comissão Encontro de Saberes foi essencial para o meu processo de valorização do conhecimento tradicional que, até então, na maioria das vezes, fui forçada a acreditar que era um conhecimento de pouco valor e que não exercia um papel importante na sociedade como o saber científico. Hoje, com certeza, participar do Encontro de Saberes me ajudou a gostar e valorizar mais a comunidade de onde vim (Comunidade Quilombola de Maria Nunes, Diamantina, MG), mostrando que o conhecimento tradicional é importante como qualquer outro conhecimento: foi importante para o meu processo de adaptação a uma nova realidade, que foi minha entrada como discente na universidade. Nela consegui encontrar um "cantinho de acolhimento", pois os encontros me proporcionavam ter contato com outras pessoas com realidades iguais às minhas. Poucos lugares na universidade me fizeram sentir tão próxima às minhas origens e me fizesse sentir tão bem. $O$ meu muito obrigada ao Encontro de Saberes. (Depoimento da discente do curso de turismo, Jéssica Gabriela Alcântara, integrante da Comissão Encontro de Saberes desde março de 2018).

Segundo o projeto construído e aprovado no Conselho de Pesquisa e PósGraduação, vinculado à Pró-Reitoria de Pesquisa e Pós Graduação da UFVJM, o E.S. em nossa instituição possui como objetivo geral: "incluir na UFVJM o diálogo com saberes pluriepstêmicos possibilitando outras modalidades de produção, transmissão e transformação de conhecimentos" 
e como objetivos específicos: "construir um diálogo permanente entre os saberes de matrizes indigenas, afrodescendentes e populares com a produção do conhecimento científico, estabelecendo ações conjuntas com o Núcleo de Estudos Afro-Brasileiros e Indígenas (NEABI/UFVJM); ofertar atividades disciplinares e de extensão em regime de alternância, a fim de consolidar uma pedagogia de envolvimento entre a universidade e a comunidade; estabelecer uma rede de articulação entre universidade, instituições, mestras e mestres, entre outros, fomentando um diálogo profundo e indissociável entre teoria e metodologia, reflexão $e$ intervenção".

Ao traçarmos tais objetivos, resultantes de muitas trocas e reflexões entre a comissão, consideramos a importância de se oferecer aos estudantes da UFVJM uma experiência de formação integral, crítica, pluriepstêmica e pluriontológica, além de fomentar a criação de redes de articulação entre universidade e os protagonistas das culturas populares, mestras e mestres dos saberes tradicionais. Pautamos também a indissociabilidade entre ensino, pesquisa e extensão e entre reflexão/intervenção (um dos princípios elencados pelo INCTI em seu documento base ${ }^{13}$ ). E defendemos que o Encontro de Saberes abre caminhos para uma formação intercultural e transversal, pois perpassa todos os cursos, comunidade acadêmica e externa, não sendo "propriedade" de nenhuma área de conhecimento específica, mas antes promovendo uma tessitura de integração de saberes, práticas e espírito crítico sobre grandes questões da humanidade.

Como justificativa estratégica, foram destacadas, no projeto, diretrizes para avaliação da pós-graduação pela Coordenação de Aperfeiçoamento de Pessoal de Nível Superior (CAPES), para as quais as universidades precisam se envolver mais com as comunidades de origem, promovendo inserção e transformação social. A Comissão também buscou articular junto à PROGRAD e PROEXC discussões acerca da potencialidade das unidades curriculares terem caráter misto, isto é, serem duplamente creditadas, como carga horária de ensino e de extensão universitária na graduação. Pois, desta forma, criar-se-ia uma oportunidade de atendimento à legislação que prevê a creditação mínima de $10 \%$ da carga horária dos cursos de graduação como extensão universitária (Estratégia 12.7 do Plano Nacional de Educação (PNE), aprovado pela Lei $\left.n^{\circ} 13.005 / 2014\right)$. No entanto, temos encontrado muita dificuldade de avanço neste diálogo, visto haver questões de limitação de sistemas informacionais apontadas pela PROGRAD e Diretoria de Tecnologia e Informação de nossa instituição. Entendemos que a instituição, dessa forma, além de deixar escapar uma importante oportunidade de atendimento à legislação, perde a oportunidade de ratificar a função social desta universidade no seu contexto de abrangência.

\footnotetext{
${ }^{13} \mathrm{INCTI/UNB/CNPq.} \mathrm{Encontro} \mathrm{de} \mathrm{Saberes:} \mathrm{bases} \mathrm{para} \mathrm{um} \mathrm{diálogo} \mathrm{inter} \mathrm{epistêmico.} \mathrm{Brasília,} 2005$.
} 
Após aprovação no Conselho de Pesquisa e Pós-Graduação (CPPG/PRPPG/UFVJM) em novembro de 2018, iniciou-se uma articulação institucional para liberação dos recursos mínimos necessários para a viabilização da primeira disciplina a ser ofertada. Após alguns meses e detalhamento de despesas previstas, foi deliberado um valor de $\mathbf{R} \$ 25.000,00$ pela reitoria da instituição. Recurso que, dentro do contexto de cortes na educação pelo executivo federal, foi diminuído em cerca de $40 \%$.

Um dos princípios da Política E.S. é o pagamento dos mestres em valor equivalente à hora/aula de um professor doutor e de seus respectivos aprendizes em valor equivalente a um bolsista de pós-graduação. Além destes, foi previsto recurso para transporte, despesas com materiais e alimentação. No entanto, com o corte, conseguimos, na prática, efetuar o pagamento das mestras e mestre (com uma carga horária para cada uma reduzida em $12 \mathrm{~h} / a u l a)$ e do transporte. Hospedamos as mestras e mestres em nossas residências (o que facilitou o vínculo, os laços) e nos dividimos sobre as despesas com alimentação. Para o evento de encerramento, também mobilizamos parcerias para um pagamento mínimo aos artistas que se fizeram presentes na programação cultural. No projeto apresentado, previmos a oferta de até quatro unidades curriculares temáticas, de conteúdos diversos, com ementas abrangentes, com carga horária de 60 horas cada: UC 1 - Artes e Ofícios, UC 2 Cosmociências, UC 3 - Arte da Cura e UC 4 - Linguagens e Narrativas.

Decidimos, coletivamente, que a primeira disciplina a ser ofertada seria "Artes da Cura". Assim, esta foi lotada no Programa de Pós-Graduação - Mestrado em Saúde, Sociedade e Ambiente - PPGSASA/UFVJM, com o apoio da parceria afetiva e administrativa da professora membro desde o princípio da Comissão, docente e atual coordenadora do programa. As matrículas a ela relacionadas possuíram caráter (i) optativo a todos os estudantes da pós-graduação da UFVJM (qualquer curso), (ii) de disciplina isolada aos interessados graduados externo à universidade e (iii) livre às pessoas da comunidade externa inscritas no projeto de extensão ${ }^{14}$. A Ementa foi inserida no sistema tal como descrita no projeto: "A disciplina contará com a presença de três mestres da tradição e seus respectivos aprendizes, de modo que os saberes de comunidades tradicionais possam ser refletidos $e$ transmitidos por seus principais representantes, garantindo seu protagonismo e o diálogo pluriepstêmico entre saberes tradicionais e saberes científicos". Foi acrescentado, a partir das mestras e mestres que aceitaram nosso convite: "Saberes e técnicas de cura. Saberes Ancestrais. O parto como acolhimento da vida. Plantas medicinais. Território e Saúde indígena".

A disciplina foi ministrada no Campus Diamantina pelas mestras e mestre, com aula inaugural que contou com apresentação do Grupo de Ginástica de Diamantina (GGD/UFVJM)

\footnotetext{
${ }^{14}$ Embora não tenha sido aprovado no âmbito da graduação, o Projeto atraiu bastante a atenção de estudantes graduandos e estes puderam se matricular como público a partir do registro deste também como Projeto de Extensão.
} 
- espetáculo "Do barro à arte"15, em homenagem à Mestra Lira Marques; videoconferência do Prof. José Jorge de Carvalho, e presencialmente do fotógrafo Lori Figueiró; contou ainda, além de três módulos ministrados na instituição (60h), com dois encontros facultativos (6h) de discussões epistemológicas; com uma vivência na Comunidade Olhos d' Água em Turmalina e outra na Aldeia Cinta Vermelha Jundiba Pataxó/Pankararu em Araçuaí; e mais um evento de encerramento.

Foi destaque a diversidade de perfis profissionais e acadêmicos presentes na turma: professores de medicina, profissionais da saúde (enfermeiros e terapeutas), lideranças de comunidades de terreiro, doulas, estudantes (de medicina, turismo, história, educação do campo), representantes de movimentos sociais, profissionais da educação, artistas, técnicos administrativos da própria instituição, militantes da permacultura, agroecologia, entre outros.

As formas de avaliação foram pensadas e realizadas em conjunto com os mestres: produção de vídeos cartas pelos alunos da pós-graduação e comunidade externa. Para os alunos da pós-graduação também foi solicitada a escrita de artigo sobre um dos temas tratados na disciplina a ser entregue aos professores parceiros como avaliação final.

Foram Mestras e Mestres participantes da disciplina:

- Mestre Dalci José de Carvalho e Dona Maria do Rosário Ramos. O Seu Dalci é mestre raizeiro, morador da comunidade Olhos D'Água, em Turmalina, MG. Por toda sua vida dedica-se aos remédios caseiros e às plantas medicinais do Cerrado, conhecimento adquirido junto aos seus familiares ancestrais. É membro histórico da Articulação Pacari e da Rede Cerrado, ambas de grande expressão e importância nacional. É também um dos autores do livro "Farmacopeia Popular do Cerrado" (2009) e do “Protocolo Comunitário Biocultural das Raizeiras do Cerrado: direito consuetudinário de praticar a medicina tradicional" (2014). Dona Maria do Rosário é agricultura e raizeira experiente, que dedica sua vida ao cuidado de várias famílias. Atualmente é uma das principais gestoras da Farmácia Popular de Remédios Caseiros da comunidade Olhos D'Água, além de ser uma guardiã de sementes crioulas do município.

- Mestra Gesilene Braz da Conceição e Mestra Maria Aparecida da Conceição de Matos participaram como docentes no segundo módulo. Cida (liderança indígena Pankararu) e Gel (liderança indígena Pataxó) são detentoras de saberes ancestrais que estruturam a vida de suas comunidades e importantes referências na luta histórica em defesa de seus territórios e dos direitos dos povos indígenas no Brasil.

\footnotetext{
${ }^{15}$ Mais info: https://ggdufvjm.wixsite.com/ggdufvjm/do-barro-a-arte. Acesso em 31.08.2020.
} 
- Mestra Maria da Conceição Carvalho e Eliane Aparecida Carvalho participaram como docentes no terceiro módulo. Dona Cotinha, experiente e sábia parteira do município de Chapada do Norte e sua Aprendiz e neta Eliane trocaram conosco saberes sobre parto, parteiras, o cuidado com o acolhimento da vida, o cuidado com a mãe, as responsabilidades e o papel de "estar junto, estar junto, estar junto" e a arte de nascer.

Nesta primeira disciplina, quatro professores membros da comissão foram - como gostamos de afirmar - parceiros afetivos dos mestres; dois destes condutores das etapas e mecanismos mais institucionais, que envolvem a oferta e dinâmica da disciplina. Membros da comissão também acompanharam de perto e afetivamente ${ }^{16}$ todo 0 trabalho de acolhimento de mestras e mestres e da turma de estudantes. Os depoimentos de todos sobre a experiência de partilha e transformação pessoal deverá gerar publicação específica, pois indicam que nossa política do cuidado, enquanto comissão, se multiplica nas práticas e nas relações que vão sendo envolvidas pelo projeto.

Como resultado das ações realizadas durante o desenvolvimento da disciplina Artes da Cura, a Comissão está organizando, em parceria com alguns dos discentes participantes e coautoria das mestras e mestres, uma cartilha, com os resultados desta disciplina; um boletim, com resumos das principais atividades realizadas pela Comissão em 2019; edição dos vídeos-registros da disciplina e de entrevistas com mestras e mestre participantes; e um ebook com artigos de estudantes que participaram da disciplina. A título de ilustração, trazemos o depoimento de um aluno desta, e integrante da comissão:

A criação do Encontro de Saberes na UFVJM tem proporcionado uma ampla visão crítica enquanto estudante, aumentando o diálogo entre mestras e mestres dos saberes tradicionais resultando em uma formação mais transversal, principalmente porque a ideia é integralizar as áreas do conhecimento sem especificar nenhuma individualmente. Enquanto comissão, uma parte importante para minha formação foi participar e auxiliar em vários eventos realizados pelo Encontro de Saberes, como: apresentação da Projeto Encontro de Saberes na UFVJM; as palestras "Cultura, Medicina e Canto Huni Kuin; e "Por que o Encontro de Saberes é fundamental para uma profunda transformação política?"; e a roda de conversa, no Museu do Diamante/IBRAM, em Diamantina, que contou com a presença do Mestre Antônio Bispo dos Santos, o Nêgo Bispo, morador do Quilombo do Saco-Curtume. Após aproximadamente um ano e meio de muito trabalho é ofertada a primeira disciplina. Contando com a presença de três mestres representantes e seus aprendizes de comunidades tradicionais do Vale do Jequitinhonha, possibilitou uma pluralidade entre saberes tradicionais e cientificos. Uma experiência inovadora no que diz respeito à troca de informações entre os futuros profissionais das agrárias (meu caso), estreitando-se com a valorização do conhecimento ancestral, saberes e técnicas de cura, plantas medicinais, o parto como acolhimento da vida, território e saúde indígena. $A$ disciplina, em seu quarto módulo, nos possibilitou uma vivência incrível na comunidade Olhos D'Água e na Aldeia Cinta Vermelha Jundiba, ambas localizadas no Médio Vale do Jequitinhonha. A percepção sobre as dificuldades dessas comunidades, tanto do trabalho com as plantas medicinais e a farmácia popular, quanto ao território indígena, em se manterem as tradições é explícita, daí a importância de aproximação e diálogo entre a

16 Importante ressaltar que, ao trazermos o afeto enquanto experiência chave do E.S, compreendemos o mesmo enquanto verbo, construção alicerçada no cotidiano da experiência, dos conflitos, diálogos, dificuldades, limites..., não apenas como sentimento. 
UFVJM e comunidades tradicionais nas suas áreas de abrangência. (Luiz Fernando Soares de Sena, discente de graduação em Agronomia pela UFVJM, militante das políticas públicas para o campo e da agroecologia, integrante da Comissão Encontro de Saberes desde março de 2018).

Como se vê na fala acima, o E.S. tem a potência de oferecer aos estudantes universitários experiências formativas ímpares, transversais e interdisciplinares, abrindo os horizontes dos futuros profissionais quanto à importância de se conhecer e valorizar os saberes e práticas tradicionais.

\section{PERCORRENDO ENCRUZILHADAS E CONFLUÊNCIAS}

Podemos enumerar alguns entre os principais problemas enfrentados pela Comissão: (i) a rigidez de procedimentos burocráticos/institucionais que não contemplam particularidades da Política, por exemplo, no pagamento das mestras e mestres; (ii) a dificuldade, ainda, de a gestão institucional compreender que o trabalho dos mestres se inicia bem antes de sua presença na universidade; (iii) a não liberação por parte da reitoria para que docentes e discentes da disciplina "Artes da Cura" pudessem levar seus filhos menores de idade em veículo oficial, para a vivência de campo prevista no projeto (proposta como experiência piloto de tempo comunidade e que demandará reflexões e publicações específicas visto a riqueza de desdobramentos gerados).

Enquanto desafios já pautados pela comissão temos: (i) garantir recursos financeiros, no atual contexto político nacional e interno à UFVJM, para a realização das próximas disciplinas e o desenvolvimento pleno de ações de extensão e pesquisa previstos como indissociáveis à política; (ii) aprofundar teórica, metodológica e pedagogicamente COM as mestras e mestres a Pedagogia da Alternância, defendida como fundamental para uma política de viabilização, permanência, salvaguarda e valorização do E.S. às comunidades de escopo da UFVJM - Gimonet (1998) enfatiza que o exercício da alternância implica em uma profunda (re)orientação da construção educativa a partir de uma perspectiva sistêmica e integradora. Esta, busca superar, por exemplo, as relações dicotômicas do tipo teoria/prática, trabalho/escola, saber acadêmico/saber popular e integrar saberes e atores em redes e interações no processo educativo que pode se dar em tempos-espaços múltiplos, integrados e integradores; (iii) problematizar e fomentar formas de registro que transcendam a lógica arquivística (escrita, colonial, utilitarista) de nossas universidades e garantam, eticamente, visibilidade, legitimação e representatividade de saberes ancestrais; (iv) expandir a Política do E.S. e a interação entre a UFVJM e a educação básica e fundamental (problematizando inclusive as expressões "básica", "fundamental" e "superior"); (v) estreitar/fortalecer laços e vínculos institucionais com as comunidades em geral; (vi) 
problematizar a questão da incorporação das línguas originais de povos tradicionais no espaço acadêmico.

Há um tempo que precisa ser dedicado à preparação das aulas, metodologia, materiais, organização de materiais, como a colheita de ervas e plantas, no caso da disciplina Artes da cura, dentre outros. Neste período compreendemos que encontros presenciais entre professores parceiros, os mestres e suas comunidades/territórios de origem, também seja fundamental. O que demanda também recursos de deslocamento e diárias, para docentes, técnicos e discentes ligados à Comissão.

Salientamos também que neste momento (2020) estamos estudando a ferramenta da "inexigibilidade licitatória", para conseguirmos viabilizar, de forma efetiva, a institucionalização do pagamento dos mestres. No entanto, entendemos que o caminho mais adequado é o da titulação de "notório saber" a todas as mestras e mestres da tradição, reconhecidos por suas comunidades de origem e pelo mapeamento cartográfico que temos realizado com e entre a rede nacional de parceiros.

Uma das preocupações da Comissão se direciona a questões práticas fora dos muros da universidade e em atuação conjunta com as comunidades. Em 2020, por exemplo, com a pandemia, chegaram-nos demandas da Aldeia Cinta Vermelha Jundiba sobre a escassez de água para irrigar as plantações, a falta de internet e a necessidade de venda do artesanato feito pela comunidade. A partir destas necessidades estabelecemos parcerias entre a Comissão, a UFVJM, a Aldeia e a Associação Jenipapense de Assistência à Infância (AJENAI) ${ }^{17}$. Assim, três projetos de extensão estão nascendo com a Aldeia, um ligado à água; outro à internet, formação e soberania tecnológica; e à divulgação e autonomia de venda da produção artesanal.

Projetos de pesquisas, já aprovados, envolvendo outros territórios, estão sendo implementados com interface na educação e, em breve, também ligados à cartografia de mestras e mestres nos Vales do Jequitinhonha e Mucuri. Um pequeno recurso foi conquistado para 2020 e as ações que ocorrerão, tais como videoaulas, estão sendo pensadas coletivamente e em respeito ao princípio de pagamento aos mestres, anteriormente mencionado.

Compreendemos que cada vez mais seja necessário pensarmos a experiência do Encontro, para além do contato entre dois indivíduos, como abertura, interação e aprendizagem (co)estabelecidas entre cosmovisões distintas. Como Mestre Nêgo Bispo afirma: é necessário "transformarmos as nossas divergências em diversidades, e na diversidade atingirmos a confluência de todas as nossas experiências"' (SANTOS, 2019, p. 69). Esta fala inspiradora é pauta para reflexões futuras.

\footnotetext{
${ }^{17}$ Mais informação sobre a Ajenai em: https://www.ajenai.org.br/ Acesso em 19.08.2020.
} 
Como se vê, o Encontro incita a academia a se (re)pensar e se (re)significar, pois, para além da lógica corrente que tem sido a do conhecimento stricto, particularizado, individual, academicista, os conhecimentos dos povos e comunidades tradicionais partem da lógica integradora e complexa e de escopo coletivo! A experiência na UFVJM, a partir de um diálogo profícuo com a prática dos colegas, alunos e comunidades promotoras da Educação do Campo, lideranças de movimentos sociais, quilombolas, indígenas, feministas (...) demanda cada vez mais consciência sobre nossas confluências. Isto não apenas soma forças em um momento de ataque à educação e às instituições de ensino, mas também nos indica que o horizonte de uma Política como a do Encontro de Saberes é o de construir, alimentar coletivamente, visibilizar, legitimar e perpetuar realidades interculturais de vivências mais solidárias, complexas e transdisciplinares.

\section{AGRADECIMENTOS}

À Comissão Encontro de Saberes da UFVJM; a todas as mestras e mestres com os quais temos construído laços na partilha de saberes e nos processos de transformação de nosso ser e estar no mundo; aos estudantes da disciplina Artes da Cura; à Aldeia Cinta Vermelha Jundiba; e ao Instituto Nacional de Ciência e Tecnologia de Inclusão no Ensino Superior e na Pesquisa (INCTI/UnB/CNPq).

\section{REFERÊNCIAS}

CARVALHO, José Jorge de. 'Espetacularização' e 'canibalização' das culturas populares na América Latina. Revista ANTHROPOLÓGICAS, ano 14, v.21, n. 1, p. 39-76, 2010.

CARVALHO, José Jorge de; FLÓREZ, Juliana F. Encuentro de Saberes: proyecto para decolonizar el conocimiento universitário eurocêntrico. Nómadas, n. 41, 131-147, 2014.

CARVALHO, José Jorge de; ÁGUAS, Carla. Encontro de Saberes: um desafio teórico, político e epistemológico. Actas Colóquio Internacional Epistemologias do Sul: aprendizagens globais Sul-Sul, Sul Norte e Norte-Sul. Boaventura de Sousa Santos e Teresa Cunha (eds). V. 01. Democratizar a Democracia. 2015.

FLÓREZ, María Juliana Flórez; OLARTE-OLARTE, María Carolina. Por una política de lo turbio. Prácticas de investigación feministas. In: FLÓREZ, M; FAGÚNDEZ, J; JIMÉNEZ, C.; RESTREPO, M.; MUELLE, C.; OJEDA-OJEDA, D.; PAZOS, M. Investigar a la intemperie. Cuestiones de método. Bogotá: Instituto Pensar, Universidad Javeriana, 2020. p. 15-57.

GIMONET, J-C. L'Alternance en formation, méthode pédagogique ou nouveau système éducatif? L'expérience des Maisons Familiales Rurales. In: DEMOL, J-N; PILON, J-M. Alternance, développement personnel et local. Paris: L'Harmattan, 1998. p. 51-66. 
INSTITUTO NACIONAL DE CIÊNCIA E TECNOLOGIA PARA INCLUSÃO NO ENSINO SUPERIOR E NA PESQUISA. Encontro de Saberes nas Universidades. Indicadores Gerais - Atualização 2010- 2019. INCTI/UnB/CNPq, Brasília, julho de 2019.

SANTOS, Antônio Bispo dos. Colonização, Quilombos: modos e significações. $2^{2}$ ed. Revista e ampliada. Associação de Ciências e Saberes para o Etnodesenvolvimento: AYó, Brasília, 2019.

UFVJM. Encontro De Saberes: uma Proposta de Formação Transversal na UFVJM. Universidade Federal dos Vales do Jequitinhonha e Mucuri. Diamantina, 2018.

WALSH, Catherine. Interculturalidad Crítica y Pedagogía De-Colonial: apuestas (des)de el in-surgir, reexistir y re-vivir. In: MEDINA, Patricia; WALSH, C; GREEND, A. Educación intercultural en América Latina: memorias, horizontes históricos y disyuntivas políticas. Ciudad de México: Plaza y Valdés, 2009. p. 25-42.

Recebido em 02 de setembro de 2020. Aprovado em 10 de fevereiro de 2021. 